Discussion Paper No. 06-032

Asset Pricing with a Reference Level of Consumption: New Evidence from the Cross-Section of Stock Returns

Joachim Grammig and Andreas Schrimpf

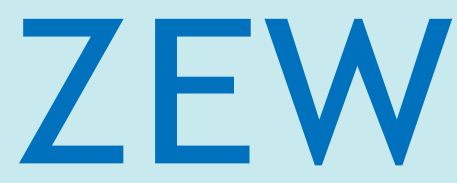

Zentrum für Europäische Wirtschaftsforschung $\mathrm{GmbH}$

Centre for European

Economic Research 
Discussion Paper No. 06-032

\title{
Asset Pricing with a Reference Level of Consumption: New Evidence from the Cross-Section of Stock Returns
}

\author{
Joachim Grammig and Andreas Schrimpf
}

Download this ZEW Discussion Paper from our ftp server:

ftp://ftp.zew.de/pub/zew-docs/dp/dp06032.pdf

Die Discussion Papers dienen einer möglichst schnellen Verbreitung von neueren Forschungsarbeiten des ZEW. Die Beiträge liegen in alleiniger Verantwortung der Autoren und stellen nicht notwendigerweise die Meinung des ZEW dar.

Discussion Papers are intended to make results of ZEW research promptly available to other economists in order to encourage discussion and suggestions for revisions. The authors are solely responsible for the contents which do not necessarily represent the opinion of the ZEW. 


\section{Non-Technical Summary}

According to classical asset pricing theory, differences in expected returns across assets must be ultimately accounted for by differences in the covariation of the asset's return with consumption growth. Despite its theoretical purity, however, the canonical consumption-based asset pricing model (CCAPM) has had a disappointing performance in past empirical tests.

In this paper, we formally estimate several extended versions of the model on common US stock market data. In particular, we focus on the extension of the standard preferences by a reference level of consumption and investigate the empirical performance of this new approach in explaining the cross-sectional variation of average stock returns compared to well-established benchmark models. Several versions of a consumption-based model with a benchmark level of consumption have recently been proposed and estimated by Garcia, Renault, and Semenov (2003). Their focus, however, was to test the conditional moment restrictions using the market portfolio and the Treasury-Bill as test assets. We extend their analysis by testing the unconditional moment restrictions of several of their proposed models on a broad cross-section of test assets, namely Fama and French's 25 portfolios sorted according to size and book-to-market.

Apart from employing this challenging set of test assets, we also motivate a specification of the reference level model which takes the return on human capital into account. Garcia et al. (2003) consider a specification, where the reference level is modelled as a function of the contemporaneous return of a market portfolio proxy. As emphasized by Roll (1977), a value-weighted stock market portfolio may not be an adequate proxy for the portfolio of total wealth since the human capital component of aggregate wealth is neglected. In this paper, we therefore consider an extended model in which the reference level does not only depend on the return of asset income, but also on the return of human capital. Following Jagannathan and Wang (1996), Lettau and Ludvigson (2001a) and Dittmar (2002) we use labor income growth as a proxy for the return on human capital.

We present empirical evidence that the model extensions by a reference level are able to substantially improve the empirical performance of the consumption-based asset pricing framework. It turns out to be essential, however, to account for human capital growth in the reference level 
specification. The human capital extended model delivers quite encouraging results from an economic perspective as well as in terms of explanatory power. The result that consumption close to or below the (estimated) reference level coincides with downturns in economic activity shows the link of the pricing kernel and the real economy. Estimated on the 25 Fama-French portfolios the human capital extended model outperforms Lettau and Ludvigson's scaled CCAPM and delivers average pricing errors comparable to the Fama-French three-factor model. 


\title{
Asset Pricing with a Reference Level of Consumption: New Evidence from the Cross-Section of Stock Returns
}

\author{
Joachim Grammig and Andreas Schrimpf*
}

First draft: May 16, 2006

This version: January 9, 2007

\begin{abstract}
This paper presents an empirical evaluation of recently proposed asset pricing models which extend the standard preference specification by a reference level of consumption. We motivate an alternative model that accounts for the return on human capital as a determinant of the reference level. Our analysis is based on a broad cross-section of test assets which provides a level playing field for a comparison to established benchmark models. The human capital extended reference level model does a good job in explaining size and value premia. Estimated on Fama and French's size and book-to-market sorted portfolios it outperforms Lettau and Ludvigson's scaled CCAPM and delivers average pricing errors comparable to the Fama-French three-factor model.
\end{abstract}

JEL Classification: G12

Keywords: Consumption-Based Asset Pricing, Cross-Section of Stock Returns, Reference Level

*Contact details authors. Joachim Grammig, University of Tübingen, Department of Economics, Mohlstr. 36. 72074 Tübingen, Germany, email: joachim.grammig@uni-tuebingen.de, phone: +49 7071 2976009, fax: +49 7071 295546; Andreas Schrimpf Center for European Economic Research (ZEW), Mannheim, P.O. Box 1034 43, 68034 Mannheim, Germany, email: schrimpf@zew.de, phone: +49 621 1235160, fax: +49 621 1235223. The paper benefited from discussions at the 2006 meetings of the Midwest Finance Association, Eastern Finance Association, German Economic Association, the German Finance Association and various seminars. We especially thank Zhi Da, H. Kraft, E. Lüders and A. Semenov for helpful comments. We are grateful to K. French and S. Ludvigson for making data used in this paper available on their webpages and to S. Frey for providing a Gauss library for GMM estimation. The usual disclaimer applies. 


\section{Introduction}

Despite its theoretical appeal, the consumption-based asset pricing model (CCAPM) has as yet achieved little empirical success in calibration exercises or formal econometric testing [See e.g. Mehra and Prescott (1985), Hansen and Singleton (1982), Cochrane (1996) or Lettau and Ludvigson (2001a)]. The empirical failure of the model has sparked a wave of research over the past 20 years aimed at improving the canonical CCAPM and making the model consistent with empirical facts.

This paper presents an empirical evaluation of recently proposed asset pricing models which extend investor preferences by a reference level of consumption. We also motivate a specification that accounts for the return on human capital as a determinant of the reference level. So far, the conditional implications of asset pricing models with a reference level have been tested using a market portfolio proxy and the Treasury-Bill as basic test assets. In our empirical investigation we use a broad cross-section of test assets, the 25 Fama-French portfolios sorted by size and book-to-market, which provides a level playing field for a comparison of reference level asset pricing models to well-established benchmark models like Lettau-Ludvigson's scaled CCAPM and the Fama-French three factor model.

Our paper is related to the literature which tackles the empirical shortcomings of consumptionbased asset pricing by modifying investor's preferences. Examples include the model proposed by Epstein and Zin (1991) who disentangle risk aversion and intertemporal substitution via a recursive utility specification and the literature on habit formation [e.g. Abel (1990), Constantinides (1990), Ferson and Constantinides (1991), Campbell and Cochrane (1999)]. The central idea of habit models is that consumers get accustomed to a certain standard of living and that their well-being depends on how much can be consumed relative to a reference level. The models considered in this paper are based on the notion of external habit formation. This implies that the reference level is not affected by the investor's decisions but depends on past aggregate consumption and can thus be interpreted as the benchmark level for the society as a whole. External habit formation expresses the idea that people want to maintain their relative standing in society often referred to as "Catching up with the Joneses" behavior, as noted in Abel (1990). When habit is a function not only of past aggregate consumption but also current 
consumption, this leads to the more general "Keeping up with the Joneses" specification as in the model by Campbell and Cochrane (1999). An important implication of this model is the counter-cyclical variation of risk-aversion that depends on the state of the economy.

In this paper we focus on a class of consumption-based asset pricing models with a reference level introduced by Garcia et al. (2003) (henceforth GRS). ${ }^{1}$ In their framework consumer preferences depend both on consumption relative to a reference level and the benchmark level itself. The (unobservable) reference level is modeled as a function of both past and current variables. The latter include a market return proxy. GRS estimate their models using a reduced set of test assets: a market portfolio proxy and the Treasury-Bill rate. We extend their analysis by estimating and testing several asset pricing models with a reference level using the 25 Fama and French portfolios sorted according to size and book-to-market as test assets, i.e. we test whether these models can account for the size and value premia in the cross-section of stock returns. The empirical performance of the reference level models is compared with classic and important recent asset pricing models like the scaled CCAPM introduced by Lettau and Ludvigson (2001b, 2001a) and the Fama-French three factor model which, on its "home turf", represents the natural benchmark. Since Lettau Ludvigson's cay-scaled CCAPM does a particularly good job in pricing the 25 Fama-French portfolios and is also solely based on macroeconomic factors it serves as another important benchmark model. Our paper is rooted in the empirical literature on representative agent models which are estimated using aggregate consumption data as pioneered by Hansen and Singleton (1982). As pointed out by Cochrane (2006), earlier papers looked mainly at statistical rejections and only considered a few test assets while recent contributions such as Yogo (2006b) and Piazzesi, Schneider, and Tuzel (2006) also focus on the economic significance of pricing errors (via RMSE comparisons and pricing error plots) for a broader set of economically interesting portfolios. Our paper is written in the same vein.

Another contribution of this paper is to propose an alternative specification that includes human capital as a determinant of the reference level. This idea draws, from a different angle, on the

\footnotetext{
${ }^{1}$ Alternative interesting approaches have been recently pursued in the literature. Chen and Ludvigson (2003) evaluate the Campbell and Cochrane (1999) model using a non-parametric specification of habit. Chen and Pakos (2006) motivate a linear factor model specification derived from the habit model by Campbell and Cochrane (1999). Yogo (2006a) proposes a consumption based model with a reference level in which a gains-loss utility function derived from behavioral and psychological considerations (loss aversion) is motivated.
} 
work by Dittmar (2002) who argues that integrating a measure of human capital into the stochastic discount factor is essential for pricing the cross-section of stock returns. ${ }^{2}$ Dittmar remains agnostic about the specific form of the utility function and approximates the SDF using a Taylor expansion. The SDF proxy he obtains is a polynomial in the return of aggregate wealth. The key factor for the empirical success of Dittmar's model is that it takes into account the return on human capital in the specification of the return on aggregate wealth.

The main results of this paper can be summarized as follows. Asset pricing models which account for a reference level of consumption considerably improve the empirical performance of the standard CCAPM. It turns out to be essential, however, to account for human capital growth in the reference level specification. The human capital extended model delivers quite encouraging results from an economic perspective as well as in terms of explanatory power. The result that consumption close to or below the (estimated) reference level coincides with downturns in economic activity shows the link of the pricing kernel and the real economy. Estimated on the 25 Fama-French portfolios the human capital extended model outperforms Lettau and Ludvigson's scaled CCAPM and delivers average pricing errors comparable to the Fama-French three-factor model.

The remainder of the paper is organized as follows. Section II reviews the theoretical framework. Section III presents data, estimation results and compares the empirical performance of asset pricing models with a reference level to benchmark models. Section IV concludes.

\section{Consumption-Based Asset Pricing with a Reference Level}

In this section we review the theoretical framework of the consumption-based asset pricing models with a reference level introduced by Garcia et al. (2003). First, a few fundamental concepts are discussed. Then we turn to the modeling strategy of the reference level and

\footnotetext{
${ }^{2}$ In a classic paper Roll (1977) argues that a value-weighted stock market portfolio may not be an adequate proxy for the total wealth portfolio since the human capital component of aggregate wealth is neglected. Important contributions which take these implications into account for their empirical work include e.g. Jagannathan and Wang (1996), Lettau and Ludvigson (2001a) and Dittmar (2002).
} 
discuss how the specification for the reference level can be augmented by human capital.

\section{A. Basic Concepts}

Consumption-based asset pricing models with a reference level are best written in their stochastic discount factor representation. When the law of one price holds, there exists a stochastic discount factor $(\mathrm{SDF}) M_{t+1}$ that prices returns:

$$
E\left[M_{t+1} R_{t+1}^{i} \mid \Phi_{t}\right]=1
$$

$R_{t+1}^{i}$ denotes the gross-return of asset $i(i=1, \ldots, N)$. $\Phi_{t}$ represents the investor's time $t$ information set. The basic setting for asset pricing models with a reference level builds on classic consumption-based asset pricing where Equation (1) results from the first order conditions of an intertemporal consumption allocation problem with time-separable utility. The stochastic discount factor can then be interpreted as the marginal rate of substitution, $M_{t+1}=\delta \frac{U^{\prime}\left(C_{t+1}\right)}{U^{\prime}\left(C_{t}\right)}$, where $\delta$ denotes the subjective discount factor and $U(\cdot)$ is the period utility function. Assuming a power utility specification $U\left(C_{t}\right)=\frac{C_{t}^{1-\gamma}}{1-\gamma}$ with $\gamma$ as the relative risk aversion (RRA) parameter the SDF is then given by

$$
M_{t+1}=\delta\left(\frac{C_{t+1}}{C_{t}}\right)^{-\gamma} .
$$

Asset pricing models with a reference level retain this basic framework but employ a differently motivated period utility function. Garcia et al. (2003) advocate an approach in which utility does not only depend on consumption $C_{t}$ but also on consumption relative to a reference level $X_{t}$. Furthermore, the reference level $X_{t}$ also enters the utility function in its absolute level,

$$
U\left(C_{t} / X_{t}, X_{t}\right)=\frac{\left(\frac{C_{t}}{X_{t}}\right)^{1-\gamma} X_{t}^{1-\psi}}{\operatorname{sign}(1-\gamma) \operatorname{sign}(1-\psi)},
$$

where $\operatorname{sign}(z)=1$ if $z \geq 0$ and $\operatorname{sign}(z)=-1$ if $z<0$, which ensures that utility is defined for all parameter values of interest. The parameter $\psi$ controls the curvature of utility over the 
benchmark level. Several alternative specifications are nested as special cases. For instance with $\psi=\gamma$, Equation (3) reduces to the power-utility CCAPM. With $\psi=1$, the reference level itself does not enter the utility function directly and investor utility depends solely on consumption relative to her benchmark. The reference level is assumed to be related to aggregate consumption by identity in conditional expectations, i.e.

$$
E_{t}\left(X_{t+\tau}\right)=E_{t}\left(C_{t+\tau}\right) \quad \forall \tau \geq 0
$$

The reference level is considered as external by the investor; it is conceived as a societal standard which the investor has in mind as benchmark for her consumption decision. Therefore, the stochastic discount factor which can be derived from Equation (3) takes the following form:

$$
M_{t+1}=\delta\left(\frac{C_{t+1}}{C_{t}}\right)^{-\gamma}\left(\frac{X_{t+1}}{X_{t}}\right)^{\gamma-\psi}
$$

\section{B. Modeling the Reference Level}

To provide an empirically testable model, further assumptions regarding the evolution of the reference level $X_{t}$ are necessary. Depending on the information set available to the investor, Garcia et al. (2003) distinguish between two possible modeling strategies. First, one could assume that the investor only has information up to period $t$ when forming her benchmark in level $t+1$. Specifically, it is assumed that the reference level in $t+1$ equals the conditional expectation of the future consumption level, where the time $t$ information set only includes past realizations of consumption levels, i.e. $X_{t+1}=E\left(C_{t+1} \mid C_{t}, C_{t-1}, \ldots\right)$ consistent with (4) for horizon $\tau=1$. In contrast to earlier papers which assume that habit only depends on consumption lagged by one period [e.g. (Abel 1990)], Garcia et al. (2003) consider that reference levels react slowly to consumption. Assuming adaptive expectations, a change in the reference level is a function of the error when forming the reference level in the previous period, $\Delta X_{t+1}=$ $\rho\left(C_{t}-X_{t}\right)$. Allowing for a constant $a$ and iterating forward on $X_{t+1}=a+\rho C_{t}+(1-\rho) X_{t}$, we obtain 


$$
X_{t+1}=\frac{a}{\rho}+\rho \sum_{i=0}^{\infty}(1-\rho)^{i} C_{t-i}
$$

In this specification, which we refer to as "pure habit formation", the habit level thus depends on past realizations of consumption with declining weights.

In a second modeling strategy Garcia et al. (2003) assume that the investor uses some information available in $t+1$ when forming the reference level $X_{t+1}$. Specifically, they argue that the (contemporaneous) return of the market portfolio qualifies as an important variable affecting the reference level. We draw on this idea and extend it by arguing that the return on human capital should be taken into account, too. This is backed by classic and recent literature. Roll's (1977) paper is the seminal reference, and Jagannathan and Wang (1996) re-emphasize that aggregate wealth also contains a human capital component. Lettau and Ludvigson (2001a) also estimate a "Scaled Human Capital CAPM" and Dittmar (2002) shows the importance of incorporating human capital into the pricing kernel. If it is true that "human capital matters" then the reference level should also be determined by the return on human capital. When wealth increases in the economy (return on the market portfolio or return on human capital move up), the investor adjusts her benchmark to a higher level. The following equation for the log change of the reference level $\Delta x_{t+1}$ takes these considerations into account:

$$
\Delta x_{t+1}=a_{0}+\sum_{i=1}^{n} a_{i} \cdot \Delta c_{t+1-i}+b \cdot r_{t+1}^{m}+c \cdot r_{t+1}^{h c} .
$$

$\Delta x_{t+1}$ denotes $\log$ consumption growth and $r_{t+1}^{m}$ the $\log$ return on financial assets (market portfolio). ${ }^{3} r_{t+1}^{h c}$ is the log return on human capital. We refer to the combination of Equation (7) and the SDF in Equation (5) as the "human capital extended (HCE) model". Garcia et al. (2003) assume that consumption growth equals the growth rate of the reference level plus noise. Hence, combining (7) and (4) at horizon one, we can write

$$
\Delta c_{t+1}=a_{0}+\sum_{i=1}^{n} a_{i} \cdot \Delta c_{t+1-i}+b \cdot r_{t+1}^{m}+c \cdot r_{t+1}^{h c}+\epsilon_{t+1}
$$

\footnotetext{
${ }^{3}$ Throughout this paper we use lower case letters to denote natural logs of the respective variable.
} 
where $\epsilon_{t+1}$ is an orthogonal innovation, $E_{t}\left[\epsilon_{t+1}\right]=0, E_{t}\left[\epsilon_{t+1} r_{t+1}^{m}\right]=0$ and $E_{t}\left[\epsilon_{t+1} r_{t+1}^{h c}\right]=0$. Reference level growth can then be written as

$$
\frac{X_{t+1}}{X_{t}}=A \prod_{i=1}^{n}\left[\frac{C_{t+1-i}}{C_{t-i}}\right]^{a_{i}}\left(R_{t+1}^{m}\right)^{b}\left(R_{t+1}^{h c}\right)^{c}
$$

where $A=\exp \left(a_{0}\right)$. Plugging Equation (9) into (5) the SDF of the HCE model is given by

$$
M_{t+1}=\delta A^{\gamma-\psi}\left[\frac{C_{t+1}}{C_{t}}\right]^{-\gamma} \prod_{i=1}^{n}\left[\frac{C_{t+1-i}}{C_{t-i}}\right]^{a_{i}(\gamma-\psi)}\left(R_{t+1}^{m}\right)^{b(\gamma-\psi)}\left(R_{t+1}^{h c}\right)^{c(\gamma-\psi)}
$$

Following Garcia et al. (2003), we define $\delta^{*}=\delta A^{\gamma-\psi}$ and $\kappa=b(\gamma-\psi)$. Equation (10) can be then rewritten as

$$
M_{t+1}=\delta^{*}\left[\frac{C_{t+1}}{C_{t}}\right]^{-\gamma} \prod_{i=1}^{n}\left[\frac{C_{t+1-i}}{C_{t-i}}\right]^{a_{i}(\gamma-\psi)}\left(R_{t+1}^{m}\right)^{\kappa}\left(R_{t+1}^{h c}\right)^{\frac{\kappa c}{b}} .
$$

Garcia et al. (2003) show that the elasticity of intertemporal substitution implied by Equation (11) is given by $\sigma=\frac{1+b(\gamma-\psi)}{\gamma}=\frac{1+\kappa}{\gamma} \cdot 4$ Hence, testing whether $\kappa$ equals zero means testing whether the elasticity of intertemporal substitution is the inverse of the coefficient of relative risk aversion as implied by the standard CCAPM with power-utility.

The SDF representation in Equation (11) is a general specification that nests various models proposed in the asset pricing literature as special cases. We turn to the estimation of these models in the next section where we also address additional assumptions for the empirical models as well as econometric issues.

\footnotetext{
${ }^{4}$ See Garcia et al. (2003) for further details. They also show that a separation between risk aversion and intertemporal substitution is only possible when the reference level does not only depend on past but also on contemporaneous variables.
} 


\section{Empirical Analysis and Results}

\section{A. A Level Playground}

This subsection describes the data used in the empirical analysis. By focussing on tests assets and data which have already been used in numerous empirical studies we want to establish a level playing field on which the different models can show their relative merits and model performance can be compared. We use data from 1951:Q4-2005:Q1, the time period for which observations of all variables are available. Our main test assets are the 25 Fama and French portfolios sorted by size and book-to-market, i.e. we assess whether reference level models are capable of accounting for the well-known size and value premia in the US cross-section of stock returns. The repository of these data is K. French's homepage. These data are only available at a monthly frequency, hence we convert them into quarterly data in order to match the frequency of the macro variables. Nominal returns are converted into real returns by deflating the nominal returns by the price index for personal consumption expenditures.

- Insert Table 1 about here -

Table 1 reports average portfolio returns of the 25 Fama-French portfolios as well as the corresponding standard deviations. Table 1 illustrates the well known stylized facts that average portfolio returns tend to decrease from small-stocks portfolios to big-stocks portfolios as well as the positive relationship between book-to-market and average returns.

K. French's homepage also serves as the source for other test asset portfolios sorted by size, book-to-market ratio, earnings-price ratio, cash flow-price ratio (ten portfolios, respectively), as well as the benchmark Fama-French factors $(S M B, H M L) .{ }^{5}$ The return on the market portfolio is the value-weighted return on all stocks traded on NYSE, AMEX and NASDAQ. The short term interest rate is the one-month Treasury-Bill from Ibbotson Associates.

\footnotetext{
${ }^{5}$ http://mba.tuck.dartmouth.edu/pages/faculty/ken.french/data_library.html. These data as well as the 25 Fama-French portfolios are regularly updated on K. French's webpage. For further details on the construction of $S M B$ and $H M L$ see Fama and French (1993).
} 
To construct managed portfolios for conditional tests we use the dividend yield on the S\&P500 obtained from from Reuters-Ecowin, the term spread, and the default spread as instruments. The term spread is defined as the difference of 10-Year Treasury Bond and three-month TBill yields. The default spread is the yield difference between BAA rated corporate bonds and AAA rated corporate bonds. The data necessary for the construction of these series are obtained from the FRED database. ${ }^{6}$ The time series of the conditioning variable cay comes from S. Ludvigson's website. ${ }^{7}$

Data on consumption and labor income (both real, per capita) are constructed from the US national accounts (NIPA tables). The measure of consumption growth is constructed from seasonally adjusted non-durables and services consumption (NIPA table 2.3.5). Price indices for non-durables and services consumption (NIPA table 2.3.4) are used to deflate the series. The time series of labor income (NIPA table 2.1) is used for calculating the growth rate of labor income needed for the estimation of the human capital augmented reference level model. Labor income is defined as wages and salaries plus transfer payments plus other labor income minus contributions to social insurance. The labor income series is deflated using the price index for personal consumption expenditures (NIPA table 2.3.4). Both real consumption and labor income are expressed in per capita terms using population values taken from NIPA table 2.1. In order to reduce potential measurement error of the return on human capital, we calculate labor income growth as a two-period moving average following Jagannathan and Wang (1996). We use the contemporaneous timing convention of Heaton and Lucas (2000) and Wang (2005).

\section{B. Empirical Setup}

To compare the empirical performance of asset pricing models with a reference level we round up the usual suspects. Along with the inevitable CAPM, the power utility CCAPM serves as the natural benchmark, but we also present results for empirically more successful models.

\footnotetext{
${ }^{6}$ http://research.stlouisfed.org/fred2/.

${ }^{7}$ http://www.econ.nyu.edu/user/ludvigsons/. The cay series is obtained as the residual from the cointegrating relationship between consumption, asset income and labor income. See Lettau and Ludvigson $(2001 \mathrm{a}, 2001 \mathrm{~b})$ for more information on data construction and on the theoretical motivation.
} 
These include Lettau-Ludvigson's scaled CCAPM as well as the Fama-French three factor model which - estimated on its "home turf" (size and book-to-market sorted portfolios) - arguably represents the toughest challenge.

In Section C we discuss results of cross-sectional tests. For GMM estimation we exploit the unconditional implications of the basic pricing equation (1). We report first stage and iterated GMM results. In order to guard against potential problems from time aggregation of consumption data, HAC standard errors are computed according to the Newey and West (1987) procedure with one lag [see Yogo (2006b)]. First-stage GMM, though less efficient, is preferable for model comparison since the average pricing errors for the test assets are identically weighted across all compared models. Estimation results for CCAPM and various reference level models are reported in Tables 2 through 6 . Results for the benchmark models are reported in Table A.1 in the appendix. Following Cochrane (2006), we assess model performance by average pricing error comparisons visualized in Figures 1 and 2. In the same vein, Table 7 ranks the models using root mean squared average pricing errors and Hansen-Jagannathan distance as performance criteria. ${ }^{8}$ We also estimate the HCE model on a set of alternative test assets. Estimation results are reported in Table 8. In Section D conditional implications of reference level models are tested using managed portfolios. These estimation results are reported in Table 9. In Section E we relate the relative position of consumption with respect to the reference level to the state of the business cycle and discuss the relationship between the reference level approach and other recently proposed macro-finance models.

\section{Cross-Sectional Tests}

\section{CCAPM with Power-Utility}

Asset pricing with a reference level is in part motivated by the empirical weakness of the power utility CCAPM. Hence, the model serves as the natural starting point for our comparisons. Estimation of the CCAPM yields the familiar results (see Table 2). The GMM estimate of the RRA parameter $\gamma$ is large but quite imprecise and the estimate of the subjective discount factor

\footnotetext{
${ }^{8}$ Details on the computation of the Hansen-Jagannathan distance measure for nonlinear SDF models are provided in the appendix.
} 
is greater than one. Hansen's (1982) $J_{T}$-test rejects the model. ${ }^{9}$ The left panel of Figure 1 shows that the model fails to account for the cross-sectional return variation of the 25 Fama-French portfolios.

- Insert Table 2 about here -

- Insert Figure 1 about here -

\section{Pure Habit Formation}

Garcia et al. (2003) propose an asset pricing model in which the reference level is solely determined by past aggregate consumption levels ("pure habit formation"). Equation (5) implies that the calculation of the model's SDF requires habit growth data which are not directly observable. Garcia et al. (2003) suggest the following strategy to resolve this problem. Under the assumption that the reference level evolves according to the adaptive expectations hypothesis, habit can be expressed as a function of past consumption levels with declining weights over time. Assuming further that the reference level in $t+1$ is equal to the conditional expected consumption in $t+1$ we can write

$$
C_{t+1}=\frac{a}{\rho}+\rho \sum_{i=0}^{\infty}(1-\rho)^{i} C_{t-i}+\epsilon_{t+1}
$$

where $\epsilon_{t+1}$ denotes an orthogonal innovation. A Koyck-transformation then leads to the following $\mathrm{MA}(1)$ representation:

$$
\Delta C_{t+1}=a-(1-\rho) \epsilon_{t}+\epsilon_{t+1}
$$

We follow Garcia et al. (2003) and employ a two-step estimation procedure which entails estimation of the MA(1) parameters $a$ and $\rho$ in the first step. Using the estimated parameters it is

\footnotetext{
${ }^{9}$ Among others, Hall and Horowitz (1996) and Altonji and Segal (1996) have pointed out that the $J_{T}$-test frequently over-rejects in small samples. As a matter of fact, all models considered in this paper are rejected, including the Fama-French three factor model (see Table A.1).
} 
then possible to construct an estimated habit growth sequence $\left\{\hat{X}_{t+1} / \hat{X}_{t}\right\}$ which can then be used to estimate the SDF parameters by GMM in the second step.

-Insert Table 3 about here--

Estimation results for the pure habit formation model are provided in Table 3. The results are ambiguous and the empirical performance of the model is disappointing. The GMM estimates of the subjective time discount factor are both smaller than one, a sensible result from an economic perspective. The RRA-coefficient estimate points towards large risk aversion, but the standard errors are very large. Based on the first-stage GMM results, the hypotheses $\psi=\gamma$ and $\psi=1$, respectively, cannot be rejected at conventional significance levels. The right panel of Figure 1 shows that the average pricing errors of the pure habit formation model are almost identical to those of CCAPM with power utility, which is also evinced by the results reported in Table 7 . We conclude that the empirical performance of the pure habit formation approach for explaining the cross-section of expected returns is quite disappointing.

\section{- Insert Figure 2 about here -}

\section{Epstein-Zin Model}

Garcia et al. (2003) show that the class of asset pricing models with a reference level nests a specification of the SDF that is similar to the one that results from the assumption that investor's utility evolves recursively as in Epstein and Zin (1989). The SDF implied by the EZ specification is obtained from equation (11) by imposing $a_{i}=0(i=1, \ldots, n)$ and $c=0$ :

$$
M_{t+1}=\delta^{*}\left(\frac{C_{t+1}}{C_{t}}\right)^{-\gamma}\left(R_{t+1}^{m}\right)^{\kappa}
$$

where $\delta^{*}=\delta \cdot \exp \left[a_{0}(\gamma-\psi)\right]$ and $\kappa=b(\gamma-\psi)$. Conceiving the Epstein-Zin specification as a special case of an asset pricing model with a reference level, one can write

$$
\Delta c_{t+1}=a_{0}+b r_{t+1}^{m}+\epsilon_{t+1}
$$


where $r_{t+1}^{m}$ denotes the log return on the market portfolio proxy. The resulting moment conditions augment the standard moment conditions implied by the EZ SDF such that all model parameters can be estimated simultaneously by GMM.

- Insert Table 4 about here -

Estimation results for the EZ model are reported in Table 4. The empirical performance is rather disappointing (see upper left panel of Figure 2 and Table 7) and the economic plausibility of the estimates is limited. First-stage and iterated GMM estimates of the RRA coefficient $\gamma$ are quite large but not different from zero at conventional levels of significance. The estimate of the subjective discount factor $\delta$ is smaller than one but too small from an economic point of view. The restriction that $\sigma=1 / \gamma$ implied by the power utility consumption-based model is rejected at the $10 \%$ significance level in the case of iterated GMM. However, neither the hypothesis $\psi=\gamma$ nor $\psi=1$ can be rejected.

\section{Garcia-Renault-Semenov Model}

Consider now a model in which the growth rate of the reference level is a function of the current period market portfolio log return $r_{t+1}^{m}$ and log consumption growth lagged by one period. This implies:

$$
\Delta c_{t+1}=a_{0}+a_{1} \cdot \Delta c_{t}+b \cdot r_{t+1}^{m}+\epsilon_{t+1}
$$

As outlined in Section B the SDF is given by:

$$
M_{t+1}=\delta^{*}\left(\frac{C_{t+1}}{C_{t}}\right)^{-\gamma}\left(\frac{C_{t}}{C_{t-1}}\right)^{\frac{\kappa a_{1}}{b}}\left(R_{t+1}^{m}\right)^{\kappa}
$$

where $R_{t+1}^{m}$ denotes the market portfolio gross return. We refer to this specification as GarciaRenault-Semenov (GRS) model. The estimation strategy is analogous to the Epstein-Zin 
model. ${ }^{10}$

- Insert Table 5 about here -

Estimation results for the GRS model are reported in Table 5. In terms of economic plausibility the results are mixed. As for the other models considered so far, the first-stage estimate of the RRA coefficient is quite large and imprecise. The first-stage GMM estimate of the subjective discount factor $\delta$ is less than one but rather small in economic terms. Based on first-stage GMM, the null hypotheses that investor preferences are of the power-utility form $(\psi=\gamma)$ and that the elasticity of intertemporal substitution $\sigma$ is equal to $1 / \gamma$ are both rejected, but only for first-stage and not for iterated GMM. The hypothesis that $\psi$ equals one cannot be rejected at conventional levels of significance. Figure 2 (upper right panel) and Table 7 show that the empirical performance of the GRS model in terms of average pricing errors is improved compared to the other reference level models considered so far.

\section{Human Capital Extended Model}

In the HCE model the reference level evolves according to Equations (7) and (8). The SDF is given in Equation (11). As for the GRS model we set $n=1$. We follow Jagannathan and Wang (1996) and Lettau and Ludvigson (2001a) and approximate the return on human capital $r^{h c}$ in Equation (7) by log labor income growth which is measured as discussed in Section III A. GMM estimation of the parameters proceeds as for the GRS model. Estimation results are reported in Table 6. The middle left panel in Figure 2 depicts the model's pricing error plot.

- Insert Table 6 about here -

As evinced by Figure 2 and Table 7, the HCE model accounts quite well for the cross-sectional variation of the returns of the 25 Fama-French portfolios, i.e. accounts quite well for the size and

\footnotetext{
${ }^{10}$ Garcia et al. (2003) suggest to include the log market return and the log consumption growth lagged by two periods as instruments for the estimation of equation (16). We do not follow their proposed strategy because market returns and consumption growth are both not well predicted by their lagged values [See discussion in Yogo (2004) and Cochrane (2006)]. In order to avoid potential estimation problems arising from weak instruments, we impose the standard OLS orthogonality conditions, i.e. use $\Delta c_{t+1}$ and $r_{t+1}^{m}$ as instruments.
} 
value premia. Along with the Fama-French three factor model it delivers the smallest average pricing errors and outperforms Lettau and Ludvigson's scaled CCAPM in terms of average pricing errors. The Hansen-Jagannathan metric is the lowest of all models. As a matter of fact, the HCE model produces average pricing errors close to those of the Fama-French three factor model estimated on its "home turf", i.e. it accounts for the size and value premia just as well as the theoretically less appealing linear factor model. The first-stage GMM estimate of the subjective time discount factor is smaller than one and economically sensible for firststage GMM. Furthermore, the HCE model estimation does actually deliver evidence against the CCAPM with power utility. Specifically, we reject at conventional levels of significance the hypothesis that the elasticity of intertemporal substitution is equal to the inverse of the RRA coefficient as well as the hypotheses $\psi=\gamma$ and $\psi=1$, respectively. The one troubling result that haunts consumption-based asset pricing models remains alive, though: As before, the RRA coefficient estimate is large and quite imprecise. Its magnitude and standard error as well as the estimate of the elasticity of intertemporal substitution are comparable to the estimates reported in Yogo (2006b).

- Insert Table 7 about here -

- Insert Table 8 about here -

In order to assess the robustness of the results, we also estimate the HCE model on an alternative set of test assets. We use 10 book-to-market (BM) portfolios, 10 size (ME) portfolios, 10 cash flow-price (CP) portfolios and 10 earnings-price (EP) portfolios. Detailed results are reported in Table 8. The estimation results broadly corroborate the conclusions for the 25 Fama-French portfolios. Evidence against the hypothesis that the elasticity of intertemporal substitution is equal to the inverse of the RRA parameter is found for the EP-sorted portfolios. For all portfolios (except CP-sorted), the subjective discount factor estimate is smaller than one. As for the 25 Fama-French portfolios, evidence against the power utility specification is found for the BM-sorted portfolios and the EP-sorted portfolios. 


\section{Managed Portfolios}

In order to test the conditional implications of asset pricing models with a reference level we form "managed portfolios" resulting from multiplying the asset returns by instruments which are elements of the investor's information set at time $t$. We want to avoid an excessive number of moment conditions. Hence we use a reduced set of basic test assets, namely the 10 Fama-French portfolios sorted by book-to-market. To construct economically meaningful managed portfolios we use as instruments financial variables suggested by the return predictability literature: the dividend yield on the S\&P500, the term spread and the default spread. These variables do not suffer from the weak instruments problem (like lagged market return and consumption growth would) since they are, to some extent, able to predict returns and consumption growth.

Table 9 contains the estimation results for the CCAPM with power utility and the pure habit formation model. Overall, the results corroborate the findings of the previous section. The performance of the CCAPM with power utility performance is unsatisfactory. The estimate of the subjective time preference parameter is smaller than one but risk aversion is negative (yet not significant). Estimates that are more sensible (in economic terms) are obtained for the pure habit model.

- Insert Table 9 about here -

The results for the other reference level model specifications are reported in Table 10. All models cannot be rejected at $1 \%$ significance level. Albeit slightly different from the results of the cross-sectional tests, the conditional tests largely speak the same language. The estimates of the subjective time preference parameter $\delta$ are economically sensible in case of the GRS and the HCE model. Compared to the cross-sectional tests, the estimates of the risk aversion parameter tend to be smaller and economically more sensible. The generally encouraging results for the HCE model are confirmed. The subjective time discount factor estimate and the estimate of the elasticity of intertemporal substitution are economically sensible and quite precise. Furthermore, the model again delivers evidence against the power utility specification.

- Insert Table 10 about here - 


\section{E. Reference Level and the Business Cycle}

Figure 3 shows the evolution of consumption in excess of the (estimated) reference level over time. The reference level series is the one implied by the HCE model estimated on the FamaFrench portfolios. The graph displays in grey shadings the official recession periods published by the NBER. The figure shows that periods of consumption close to or below the reference level coincide with downturns in economic activity. Accordingly, allowing for a dependence of the utility specification on the state of the business cycle may indeed be the main driving force for the empirical success of the reference level approach in explaining the cross-section of returns.

Interpreted in this way, our results are related to the recent work most notably by Yogo (2006b) and Piazzesi et al. (2006). In these models, the relative importance of durables consumption versus nondurables (Yogo) and the share of housing consumption versus total consumption (Piazessi et al.), respectively, play a similar role as consumption relative to the reference level.

- Insert Figure 3 about here -

\section{Conclusion}

This paper presents an empirical evaluation of recently proposed asset pricing models which extend investor preferences by a reference level of consumption. It also motivates a specification that accounts for the return on human capital as a determinant of the reference level which we refer to as "Human Capital-Extended (HCE) model". So far, the conditional implications of asset pricing models with a reference level have been tested using a market portfolio proxy and the Treasury-Bill as basic test assets. In our empirical investigation we use a broad crosssection of test assets, Fama and French's 25 portfolios sorted by size and book-to-market, which provides a level playing field for a comparison of reference level asset pricing models to wellestablished benchmark models like Lettau-Ludvigson's scaled CCAPM and the Fama-French three factor model. We focus our attention on the class of asset pricing models with a reference 
level of consumption proposed by Garcia et al. (2003). An important feature of their approach is to model the reference level also as a function of the contemporaneous return on the market portfolio.

Asset pricing models with a reference level of consumption can considerably improve the empirical performance of the CCAPM. However, it is crucial to allow for the return on human capital when modeling the reference level. The HCE model accounts for value and size effects in average returns just as well as the Fama-French three factor model. Estimated on the 25 Fama-French portfolios the HCE model outperforms Lettau and Ludvigson's scaled CCAPM in terms of average pricing errors. Parameter estimates and economic implications are quite sensible. Consumption close to or below the reference level implied by the HCE model coincides with downturns in economic activity which establishes the link between pricing kernel and the real economy. These overall encouraging results need to be taken with a grain of salt. All reference level models considered in this paper, including the HCE model, still require a high degree of risk-aversion. They therefore do not yet deliver a true solution to the "equity premium puzzle" which motivated their introduction in the first place. Cochrane's (2006, p.24) conclusion that "maybe we have to accept high risk aversion, at least for reconciling aggregate consumption with market returns in this style of model" seems to apply to consumption-based asset pricing models with a reference level, too. 


\section{REFERENCES}

Abel, A., 1990, Asset prices under habit formation and catching up with the Joneses, The American Economic Review 80, 38-42.

Altonji, J.G., and L. M. Segal, 1996, Small-sample bias in GMM estimation of covariance structures, Journal of Business and Economic Statistics 14, 353-366.

Campbell, John Y., and John H. Cochrane, 1999, By force of habit: A consumption based explanation of aggregate stock market behavior, Journal of Political Economy 107, 205251.

Chen, Huafeng, and Michal Pakos, 2006, Habit formation, time-varying risk aversion and crosssection of expected returns, Working Paper, University of British Columbia at Vancouver.

Chen, Xiaohong, and Sidney Ludvigson, 2003, Land of addicts? An empirical investigation of habit-based asset pricing models, Working paper, New York University.

Cochrane, John H., 1996, A cross-sectional test of an investment-based asset pricing model, Journal of Political Economy 104, 572-621.

Cochrane, John H., 2006, Financial markets and the real economy, Working paper, University of Chicago.

Constantinides, George M., 1990, Habit formation: A resolution of the equity premium puzzle, Journal of Political Economy 98, 519-543.

Dittmar, Robert F., 2002, Nonlinear pricing kernels, kurtosis preference, and evidence from the cross section of equity returns, Journal of Finance 57, 369-403.

Epstein, Larry, and Stanley Zin, 1989, Substitution, risk aversion, and the temporal behavior of consumption growth and asset returns I: A theoretical framework, Econometrica 57, $937-969$.

Epstein, Larry, and Stanley Zin, 1991, Substitution, risk aversion, and the temporal behavior of consumption growth and asset returns: An empirical analysis, Journal of Political Economy 99, 263-286. 
Fama, Eugene F., and Kenneth R. French, 1993, Common risk factors in the returns on stocks and bonds, Journal of Financial Economics 33, 3-56.

Ferson, Wayne E., and George M. Constantinides, 1991, Habit persistence and durability in aggregate consumption; empirical tests, Journal of Financial Economics 29, 199-240.

Garcia, René, Eric Renault, and Andrei Semenov, 2003, A consumption CAPM with a reference level, Working paper, Université de Montreal.

Hall, P., and J.L. Horowitz, 1996, Bootstrap critical values for tests based on generalizedmethod-of-moments estimators, Econometrica 64, 1517-1527.

Hansen, Lars P., 1982, Large sample properties of generalized method of moments estimators, Econometrica 50, 1029-1054.

Hansen, Lars P., and Ravi Jagannathan, 1997, Assessing specification errors in stochastic discount factor models, Journal of Finance 52, 557-590.

Hansen, Lars P., and Kenneth J. Singleton, 1982, Generalized instrumental variables estimation of nonlinear rational expectations models, Econometrica 50, 1296-1286.

Heaton, John, and Deborah Lucas, 2000, Portfolio choice and asset prices: The importance of entrepreneurial risk, Journal of Finance 55, 1163-1198.

Hodrick, Robert J., and Xiaoyan Zhang, 2001, Evaluating the specification errors of asset pricing models, Journal of Financial Economics 62, 327-376.

Jagannathan, Ravi, and Yong Wang, 2006, Lazy investors, discretionary consumption, and the cross-section of stock returns, forthcoming Journal of Finance.

Jagannathan, Ravi, and Zhenyu Wang, 1996, The conditional CAPM and the cross-section of expected returns, Journal of Finance 51, 3-53.

Lettau, Martin, and Sidney Ludvigson, 2001a, Ressurrecting the (C)CAPM: A cross-sectional test when risk premia are time-varying, Journal of Political Economy 109, 1238-1287. 
Lettau, Martin, and Sydney Ludvigson, 2001b, Consumption, aggregate wealth, and expected stock returns, Journal of Finance 56, 815-849.

Mehra, Rajnish, and Edward Prescott, 1985, The equity premium: A puzzle, Journal of Monetary Economics 15, 145-161.

Newey, Whitney K., and Kenneth D. West, 1987, A simple, positive semi-definite, heteroskedasticity and autocorrelation consistent covariance matrix, Econometrica: Journal of the Econometric Society 55, 703-708.

Parker, Jonathan A., and Christian Julliard, 2005, Consumption risk and the cross section of expected returns, Journal of Political Economy 113, 185-222.

Piazzesi, Monika, Martin Schneider, and Selale Tuzel, 2006, Housing, consumption and asset prices, Journal of Financial Economics (forthcoming).

Roll, Richard W., 1977, A critique of the asset pricing theory's tests, Journal of Financial Economics 4, 129-176.

Wang, Yong, 2005, A comparison of factor models for explaining the cross section of stock returns, Working paper, Kellogg School of Management.

Yogo, Motohiro, 2004, Estimating the elasticity of intertemporal substitution when instruments are weak, Review of Economics and Statistics 86, 797-810.

Yogo, Motohiro, 2006a, Asset prices under habit formation and reference-dependent preferences, Working paper, University of Pennsylvania.

Yogo, Motohiro, 2006b, A consumption-based explanation of expected stock returns, Journal of Finance 61, 539-580. 


\section{Appendix}

\section{A. Details on Hansen-Jagannathan Distance}

In the papers by Jagannathan and Wang (1996), Hodrick and Zhang (2001) and Jagannathan and Wang (2006) the Hansen-Jagannathan (HJ) distance is used as a convenient metric for model comparison purposes. The (sample) HJ distance is the square root of the minimum of a GMM objective function that uses the inverse of the sample second moment matrix of asset returns $G_{T}=\left[T^{-1} \sum_{t=1}^{T} R_{t} R_{t}^{\prime}\right]^{-1}$, where $R_{t}$ is a $N \times 1$ vector of asset returns, as weighting matrix:

$$
\delta_{T}=\left[\min _{\theta} g_{T}(\theta)^{\prime} G_{T} g_{T}(\theta)\right]^{0.5}
$$

$g_{T}(\theta)$ denotes the vector of sample moment conditions implied by the asset pricing model. The HJ distance is suitable for model comparisons as the weighting matrix is not model dependent. Hansen and Jagannathan (1997) show that the distance between the set of true stochastic discount factors and the SDF proxy of the asset pricing model is minimized, when the (sub)optimal weighting matrix $G_{T}$ is used for GMM estimation. Parker and Julliard (2005) extend these results and derive the distribution of the HJ-distance for non-linear pricing kernels. They show that under the null hypothesis (correct SDF) $T \delta_{T}^{2}$ is distributed as a weighted sum of $\chi^{2}(1)$ random variables. Following Jagannathan and Wang (1996) and Parker and Julliard (2005) we obtain the $p$-values reported in Table 7 via simulation (we use 10,000 replications).

As outlined in the main text, we use for GMM estimation of Epstein-Zin (EZ), Garcia-RenaultSemonov (GRS) and Human Capital-Extended (HCE) model $k$ additional moment conditions that augment the moment conditions for the test assets. For these models, the GMM weighting matrix is given by

$$
W_{T}=\left[\begin{array}{cc}
G_{T} & \mathbf{0} \\
\mathbf{0} & I_{k}
\end{array}\right] \text {, }
$$


where $\mathbf{0}$ is a corresponding matrix of zeros. To ensure comparability between models, we compute the HJ-distance for EZ, GRS and HCE model using the first $N$ moment conditions implied by the asset returns.

\section{B. Estimation Results Linear Factor Models}

- Insert Table A.1 about here - 
Table 1

Summary Statistics for the Test Assets (in \%)

\begin{tabular}{cccccccccccc}
\hline & \multicolumn{10}{c}{ Book-to-Market Equity Quintiles } \\
& $B 1$ & $B 2$ & $B 3$ & $B 4$ & $B 5$ & $B 1$ & $B 2$ & $B 3$ & $B 4$ & $B 5$ \\
\hline Size Quintiles & \multicolumn{9}{c}{ Means } \\
$S 1$ & 2.05 & 3.60 & 3.69 & 4.38 & 4.72 & 15.68 & 13.41 & 11.67 & 11.16 & 12.24 \\
$S 2$ & 2.44 & 3.26 & 3.84 & 4.04 & 4.37 & 13.85 & 11.62 & 10.25 & 10.19 & 11.10 \\
$S 3$ & 2.72 & 3.40 & 3.41 & 3.83 & 4.10 & 12.43 & 10.20 & 9.39 & 9.45 & 10.49 \\
$S 4$ & 2.86 & 2.86 & 3.57 & 3.65 & 3.77 & 11.30 & 9.52 & 8.93 & 8.98 & 10.32 \\
$S 5$ & 2.57 & 2.71 & 2.90 & 2.90 & 3.06 & 9.00 & 8.07 & 7.31 & 7.70 & 8.96 \\
\hline \hline
\end{tabular}

Note: The table reports means and corresponding standard deviations of the real quarterly returns on the 25 portfolios by Fama and French (1993). The table is organized as follows: $S 1 / B 1$ contains the average return of the portfolio that includes the smallest stocks in terms of market capitalization and at the same time with the lowest book-to-market ratio; $S 5 / B 5$ contains the average return of the portfolio that includes the biggest stocks with the highest book-to-market ratios and so forth. Sample: 1951:Q4-2005:Q1. 
Table 2

CCAPM: Estimation Results

\begin{tabular}{cccccc}
\hline & \multicolumn{3}{c}{ First-stage GMM } & & \multicolumn{2}{c}{ Iterated } & GMM \\
& Estimate & t-Stat. & & Estimate & t-Stat. \\
\hline$\delta$ & 1.37 & 3.72 & $\delta$ & 1.05 & 4.36 \\
$\gamma$ & 76.32 & 1.08 & $\gamma$ & 15.03 & 0.34 \\
\hline$J_{T}$ & 81.9 & $(0.00)$ & $J_{T}$-Stat. & 83.6 & $(0.00)$ \\
\hline \hline
\end{tabular}

Note: The estimation is based on (1) using the SDF specification in (2). Both results of first-stage and iterated GMM are provided. $J_{T}$ is the value of Hansen's (1982) test statistic of the overidentifying restrictions, the $p$-value is in parentheses. Sample: 1951:Q4-2005:Q1. 
Table 3

Pure Habit Model: Estimation Results

\begin{tabular}{|c|c|c|c|c|c|}
\hline & \multicolumn{2}{|c|}{ First-stage $G M M$} & & \multicolumn{2}{|c|}{ Iterated GMM } \\
\hline & Estimate & $t$-Stat. & & Estimate & $t$-Stat. \\
\hline$\delta$ & 0.99 & 1.12 & $\delta$ & 0.68 & 2.00 \\
\hline$\gamma$ & 75.27 & 1.24 & $\gamma$ & 40.41 & 0.67 \\
\hline$\psi$ & 14.93 & 0.09 & $\psi$ & -44.57 & -0.51 \\
\hline$\gamma-\psi$ & 60.33 & 0.41 & $\gamma-\psi$ & 84.98 & 1.17 \\
\hline $1-\psi$ & -13.93 & -0.09 & $1-\psi$ & 45.57 & 0.53 \\
\hline$J_{T}$-Stat. & 86.6 & $(0.00)$ & $J_{T}$-Stat. & 105.8 & $(0.00)$ \\
\hline
\end{tabular}

Note: An $\operatorname{ARIMA}(0,1,1)$-model is estimated in order to obtain an estimate of habit as a function of past consumption levels. In the second step, we substitute habit growth in the stochastic discount factor by its estimate. The resulting moment conditions are estimated by GMM. $J_{T}$ is the value of Hansen's (1982) test statistic of the overidentifying restrictions, the $p$-value is in parentheses. The sample period is 1951:Q4-2005:Q1. Standard errors of indirectly estimated parameters are calculated according to the Delta Method. 
Table 4

Epstein-Zin Model: Estimation Results

\begin{tabular}{cccccc}
\hline & \multicolumn{2}{c}{ First-stage } & GMM & & \multicolumn{2}{c}{ Iterated } & $G M M$ \\
& Estimate & $t$-Stat. & & Estimate & $t$-Stat. \\
\hline$\delta^{*}$ & 1.35 & 4.58 & $\delta^{*}$ & 1.01 & 4.58 \\
$\gamma$ & 90.63 & 1.61 & $\gamma$ & 24.37 & 0.56 \\
$\kappa$ & 1.95 & 1.21 & $\kappa$ & 2.38 & 1.82 \\
\hline$a_{0}$ & 0.005 & 14.78 & $a_{0}$ & 0.005 & 15.42 \\
$b$ & 0.009 & 2.91 & $b$ & 0.006 & 1.93 \\
\hline$\gamma-\psi$ & 210.84 & 1.24 & $\gamma-\psi$ & 413.74 & 1.53 \\
$\psi$ & -120.21 & -0.63 & $\psi$ & -389.38 & -1.40 \\
$1-\psi$ & 121.21 & 0.63 & $1-\psi$ & 390.38 & 1.41 \\
$\delta$ & 0.45 & 1.01 & $\delta$ & 0.11 & 0.67 \\
$\sigma$ & 0.03 & 1.41 & $\sigma$ & 0.14 & 0.80 \\
\hline$J_{T}$-Stat. & 84.1 & $(0.00)$ & $J_{T}$-Stat. & 83.3 & $(0.00)$ \\
\hline \hline
\end{tabular}

Note: Estimation is based on unconditional moment conditions using the 25 Fama-French portfolios sorted by size and book-to-market. The specification of the SDF is given in Equation (14). The moment conditions are estimated jointly with the linear Equation (15). $J_{T}$ is the value of Hansen's (1982) test statistic of the overidentifying restrictions, the $p$-value is in parentheses. The sample period is 1951:Q42005:Q1. Standard errors of indirectly estimated parameters are calculated by the Delta Method. 
Table 5

Garcia-Renault-Semenov Model: Estimation Results

\begin{tabular}{cccccc}
\hline & \multicolumn{2}{c}{ First-stage } & GMM & & \multicolumn{2}{c}{ Iterated $G M M$} \\
& Estimate & $t$-Stat. & & Estimate & $t$-Stat. \\
\hline$\delta^{*}$ & 0.42 & 1.40 & $\delta^{*}$ & 0.68 & 2.58 \\
$\gamma$ & 215.76 & 2.90 & $\gamma$ & 61.77 & 1.11 \\
$\kappa$ & 8.33 & 2.33 & $\kappa$ & 2.72 & 1.42 \\
\hline$a_{0}$ & 0.024 & 0.96 & $a_{0}$ & 0.010 & 7.09 \\
$a_{1}$ & 0.611 & 2.22 & $a_{1}$ & 0.336 & 5.68 \\
$b$ & 0.024 & 5.75 & $b$ & 0.010 & 3.76 \\
\hline$\gamma-\psi$ & 347.47 & 2.18 & $\gamma-\psi$ & 282.12 & 1.47 \\
$\psi$ & -131.71 & -0.81 & $\psi$ & -220.35 & -1.35 \\
$1-\psi$ & 132.71 & 0.82 & $1-\psi$ & 221.35 & 1.36 \\
$\delta$ & 0.25 & 1.00 & $\delta$ & 0.27 & 1.02 \\
$\sigma$ & 0.04 & 2.41 & $\sigma$ & 0.06 & 1.96 \\
\hline$J_{T}$-Stat. & 88.0 & $(0.00)$ & $J_{T}$-Stat. & 78.8 & $(0.00)$ \\
\hline \hline
\end{tabular}

Note: Estimation is based on unconditional moment conditions using the 25 Fama-French portfolios sorted by size and book-to-market. The specification of the SDF is given in Equation (17). The moment conditions for the test asset returns are estimated jointly with the moment conditions implied by the linear Equation (16). $J_{T}$ is the value of Hansen's (1982) test statistic of the overidentifying restrictions, the $p$ value is in parentheses. The sample period is 1951:Q4-2005:Q1. Standard errors of indirectly estimated parameters are calculated by the Delta Method. 
Table 6

Human Capital Extended Model: Estimation Results

\begin{tabular}{|c|c|c|c|c|c|}
\hline & \multicolumn{2}{|c|}{ First-stage GMM } & & \multicolumn{2}{|c|}{ Iterated GMM } \\
\hline & Estimate & $t$-Stat. & & Estimate & $t$-Stat. \\
\hline$\delta^{*}$ & 0.56 & 1.27 & $\delta^{*}$ & 0.33 & 2.42 \\
\hline$\gamma$ & 282.18 & 2.64 & $\gamma$ & 180.11 & 3.13 \\
\hline$\kappa$ & 3.76 & 1.02 & $\kappa$ & 3.88 & 2.46 \\
\hline$a_{0}$ & -0.001 & -0.20 & $a_{0}$ & 0.003 & 5.97 \\
\hline$a_{1}$ & 0.336 & 0.65 & $a_{1}$ & 0.093 & 1.45 \\
\hline$b$ & 0.017 & 3.04 & $b$ & 0.008 & 3.02 \\
\hline$c$ & 0.747 & 0.92 & $c$ & 0.363 & 6.05 \\
\hline$\gamma-\psi$ & 216.54 & 1.22 & $\gamma-\psi$ & 517.41 & 4.76 \\
\hline$\psi$ & 65.64 & 0.32 & $\psi$ & -337.30 & -3.54 \\
\hline $1-\psi$ & -64.64 & -0.31 & $1-\psi$ & 338.30 & 3.55 \\
\hline$\delta$ & 0.68 & 0.97 & $\delta$ & 0.08 & 1.52 \\
\hline$\sigma$ & 0.02 & 1.22 & $\sigma$ & 0.03 & 3.13 \\
\hline$J_{T}$-Stat. & 56.3 & $(0.00)$ & $J_{T}$-Stat. & 50.2 & $(0.00)$ \\
\hline
\end{tabular}

Note: Estimation is based on unconditional moment conditions using the 25 Fama-French portfolios sorted by size and book-to-market. The specification of the SDF is given in Equation (11), where $n$ is set to one. The moment conditions for the test asset returns are estimated jointly with the moment conditions implied by the linear Equation (8), also setting $n=1 . J_{T}$ is the value of Hansen's (1982) test statistic of the overidentifying restrictions, the $p$-value is in parentheses. The sample period is 1951:Q4-2005:Q1. Standard errors of indirectly estimated parameters are calculated by the Delta Method. 
Table 7

Summary of Model Comparison Statistics

\begin{tabular}{lccccc}
\hline Model & RMSE & HJ-dist. & $p$-val. & $J_{H J}$ & $p$-val. \\
\hline Human Capital Extended & 0.33 & 0.44 & 0.43 & 36.6 & 0.27 \\
Fama-French & 0.33 & 0.52 & 0.00 & 67.1 & 0.00 \\
Lettau-Ludvigson & 0.40 & 0.57 & 0.00 & 89.6 & 0.00 \\
Garcia-Renault-Semenov & 0.55 & 0.56 & 0.00 & 81.1 & 0.00 \\
Epstein-Zin & 0.59 & 0.57 & 0.00 & 84.2 & 0.00 \\
Pure habit & 0.63 & 0.59 & 0.00 & 92.4 & 0.00 \\
Power utility CCAPM & 0.64 & 0.59 & 0.00 & 83.8 & 0.00 \\
CAPM & 0.64 & 0.58 & 0.00 & 82.3 & 0.00 \\
\hline \hline
\end{tabular}

Note: The table contains a summary of model performance evaluation. The test assets are 25 size and book-to-market sorted portfolios. RMSE is the root mean square average pricing error based on first-stage GMM, HJ-dist. refers to the Hansen-Jagannathan distance metric, $J_{H J}$ is the $J_{T}$-statistic when using the HJ weighting matrix. Details on HJ-GMM estimation are provided in appendix A. The $p$-value for the model test based on the HJ-distance is determined by simulation (see appendix). The sample period is 1951:Q42005:Q1. 


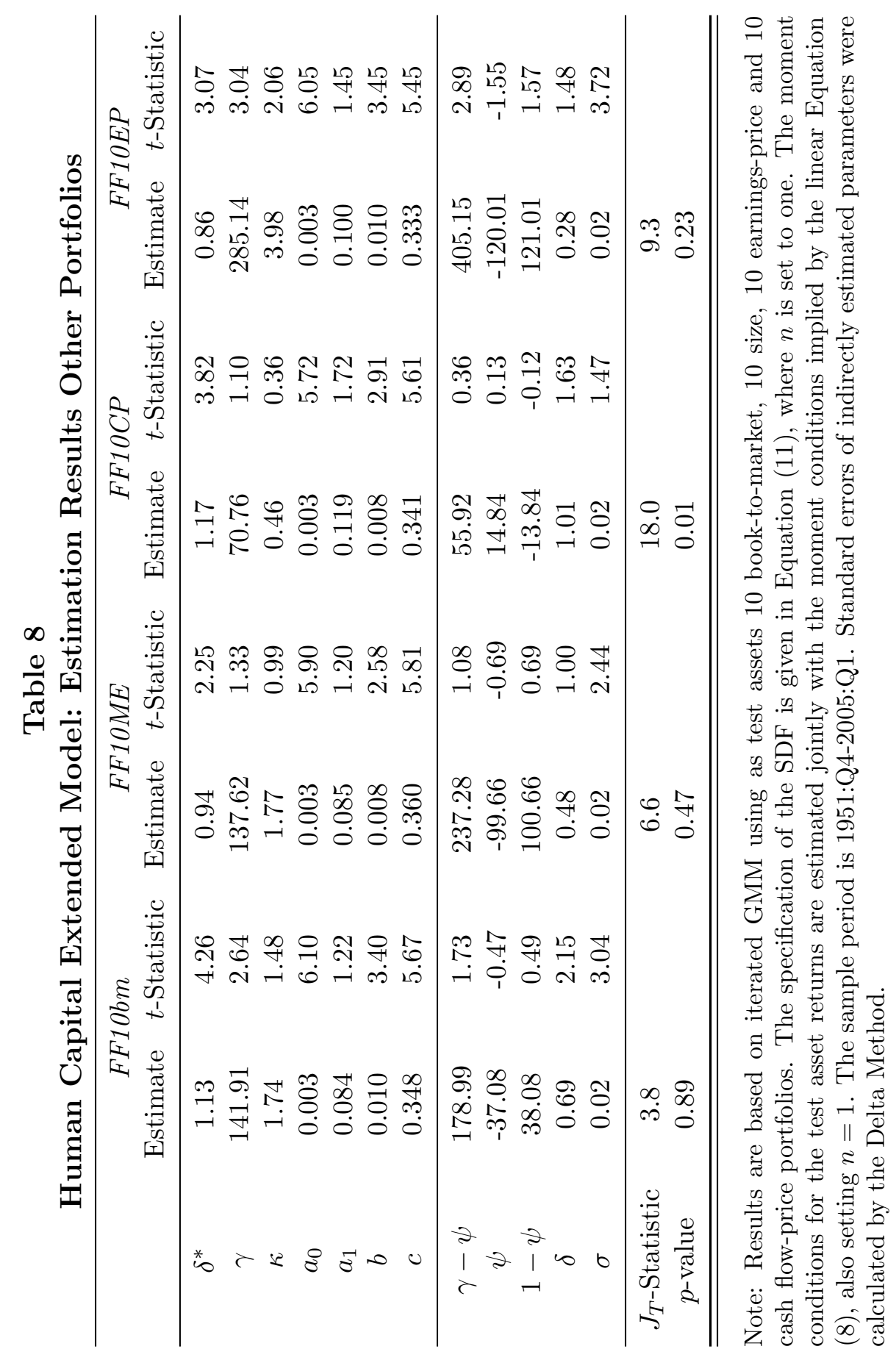


Table 9

Consumption-Based and Pure Habit Model, Managed Portfolios

\begin{tabular}{cccccc}
\hline & \multicolumn{2}{c}{ Power Utility CCAPM } & & \multicolumn{2}{c}{ Pure Habit } \\
& Estimate & $t$-Statistic & & Estimate & $t$-Statistic \\
\hline$\delta$ & 0.97 & 16.88 & $\delta$ & 0.97 & 14.93 \\
$\gamma$ & -1.52 & -0.14 & $\gamma$ & 8.49 & 0.62 \\
\hline & & & $\gamma-\psi$ & 8.95 & 2.19 \\
& & & $\psi$ & -0.46 & -0.04 \\
& & & $1-\psi$ & 1.46 & 0.12 \\
\hline$J_{T}$-Statistic & 46.4 & $(0.16)$ & $J_{T}$-Statistic & 53.4 & $(0.04)$ \\
\hline \hline
\end{tabular}

Note: Estimation is by iterated GMM using test asset returns scaled by instruments $z_{t}$, where $z_{t}$ contains a constant, the dividend yield $D I V_{t}$, the term spread, TERM and the default spread $D E F_{t}$. The test assets are 10 Fama-French portfolios sorted by book-to-market. The sample period is 1951:Q4-2005:Q1. Standard errors of indirectly estimated parameters were calculated by the Delta Method. 


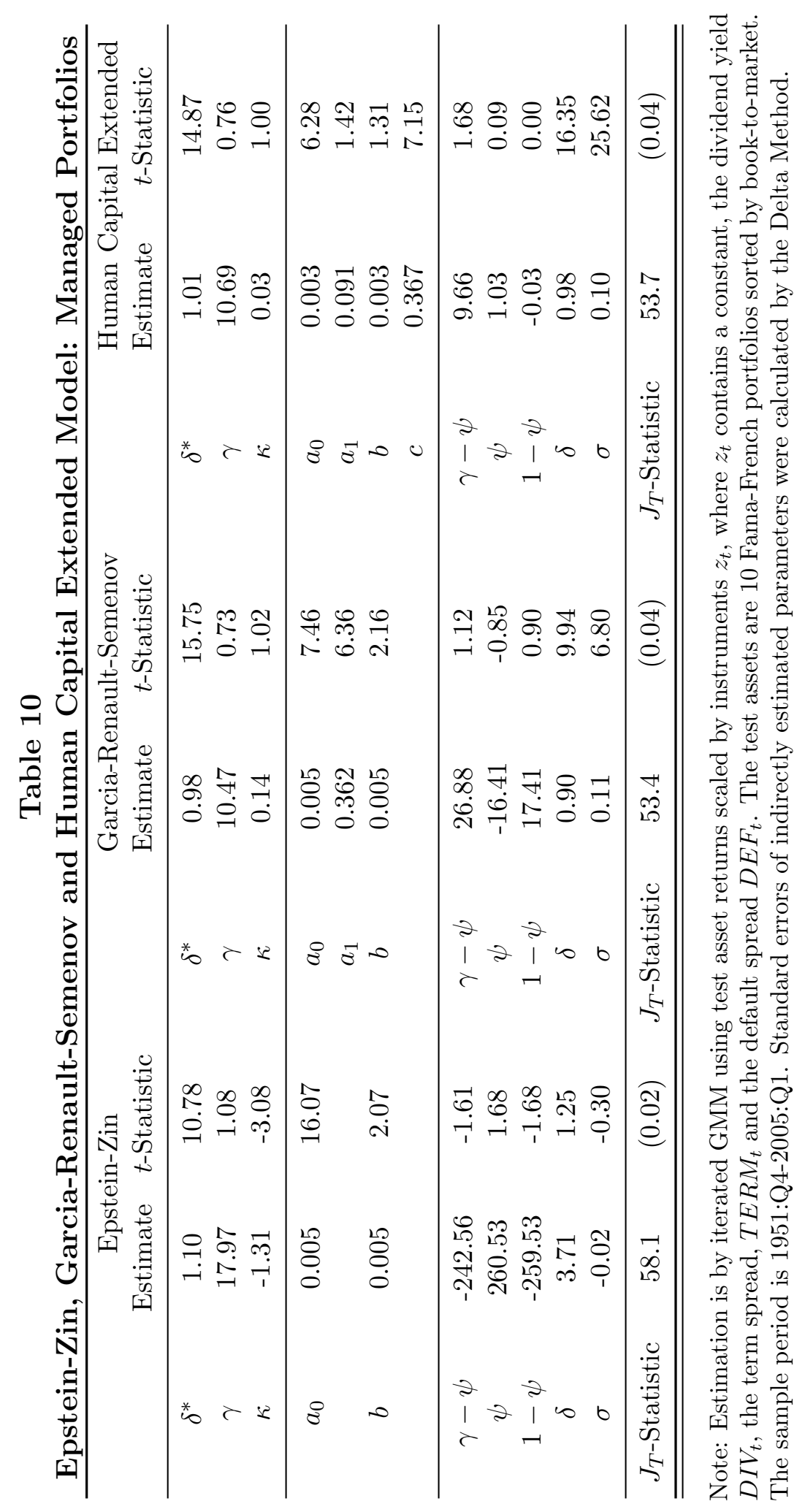


Table A.1

Linear Factor Models: Estimation Results

\begin{tabular}{|c|c|c|c|c|c|c|}
\hline CCAPM & $b_{0}$ & & & $b_{\Delta c}$ & $J_{T}$-Statistic & $p$-value \\
\hline \multicolumn{7}{|l|}{ First-Stage: } \\
\hline Coefficient & 1.59 & & & -113.50 & 75.3 & 0.00 \\
\hline$t$-Statistic & 3.31 & & & -1.31 & & \\
\hline Iterated: & & & & & & \\
\hline Coefficient & 1.12 & & & -27.66 & 83.1 & 0.00 \\
\hline$t$-Statistic & 4.75 & & & -0.65 & & \\
\hline Scaled CCAPM & $b_{0}$ & $b_{\text {cay }}$ & $b_{c a y \cdot \Delta c}$ & $b_{\Delta c}$ & $J_{T}$-Statistic & $p$-value \\
\hline \multicolumn{7}{|l|}{ First-Stage: } \\
\hline Coefficient & 1.03 & 1.28 & -41.81 & -158.61 & 88.4 & 0.00 \\
\hline$t$-Statistic & 1.51 & 2.16 & -0.35 & -2.08 & & \\
\hline Iterated: & & & & & & \\
\hline Coefficient & 0.79 & 0.54 & 22.00 & -67.91 & 84.0 & 0.00 \\
\hline$t$-Statistic & 2.99 & 1.99 & 0.47 & -1.56 & & \\
\hline CAPM & $b_{0}$ & & & $b_{m}$ & $J_{T}$-Statistic & $p$-value \\
\hline \multicolumn{7}{|l|}{ First-Stage: } \\
\hline Coefficient & -0.44 & & & 1.37 & 82.5 & 0.00 \\
\hline$t$-Statistic & -0.28 & & & 0.89 & & \\
\hline Iterated: & & & & & & \\
\hline Coefficient & -1.26 & & & 2.18 & 82.4 & 0.00 \\
\hline$t$-Statistic & -1.12 & & & 1.97 & & \\
\hline Fama-French & $b_{0}$ & $b_{m}$ & $b_{S M B}$ & $b_{H M L}$ & $J_{T}$-Statistic & $p$-value \\
\hline \multicolumn{7}{|l|}{ First-Stage: } \\
\hline Coefficient & 0.91 & 3.97 & -4.58 & -2.43 & 67.3 & 0.00 \\
\hline $\begin{array}{l}t \text {-Statistic } \\
\text { Iterated: }\end{array}$ & 13.60 & 1.81 & -2.64 & -1.25 & & \\
\hline Coefficient & 0.99 & 1.93 & -4.09 & -4.60 & 63.6 & 0.00 \\
\hline$t$-Statistic & 18.28 & 1.15 & -2.65 & -2.87 & & \\
\hline
\end{tabular}

Note: The table reports GMM estimation results for the benchmark linear factor models. The specification of the SDF is a linear function of $K$ factors $M_{t+1}=b_{0}+b_{1}^{\prime} f_{t+1}$. The models differ in their specification of the factors. The linearized CCAPM is a single-factor model using log consumption growth $f_{t+1}=\Delta c_{t+1}$. Lettau/Ludvigson's scaled CCAPM has three factors $f_{t+1}=$ $\left[\text { cay }_{t} ; \text { cay }_{t} \Delta c_{t+1} ; \Delta c_{t+1}\right]^{\prime}$. In the case of the CAPM the excess return on the market portfolio is the only factor, $f_{t+1}=R_{t+1}^{m}$. The Fama-French model is specified as $f_{t+1}=\left[R_{t+1}^{m} ; S M B_{t+1} ; H M L_{t+1}\right]^{\prime}$. The sample period is 1951:Q4-2005:Q1. 

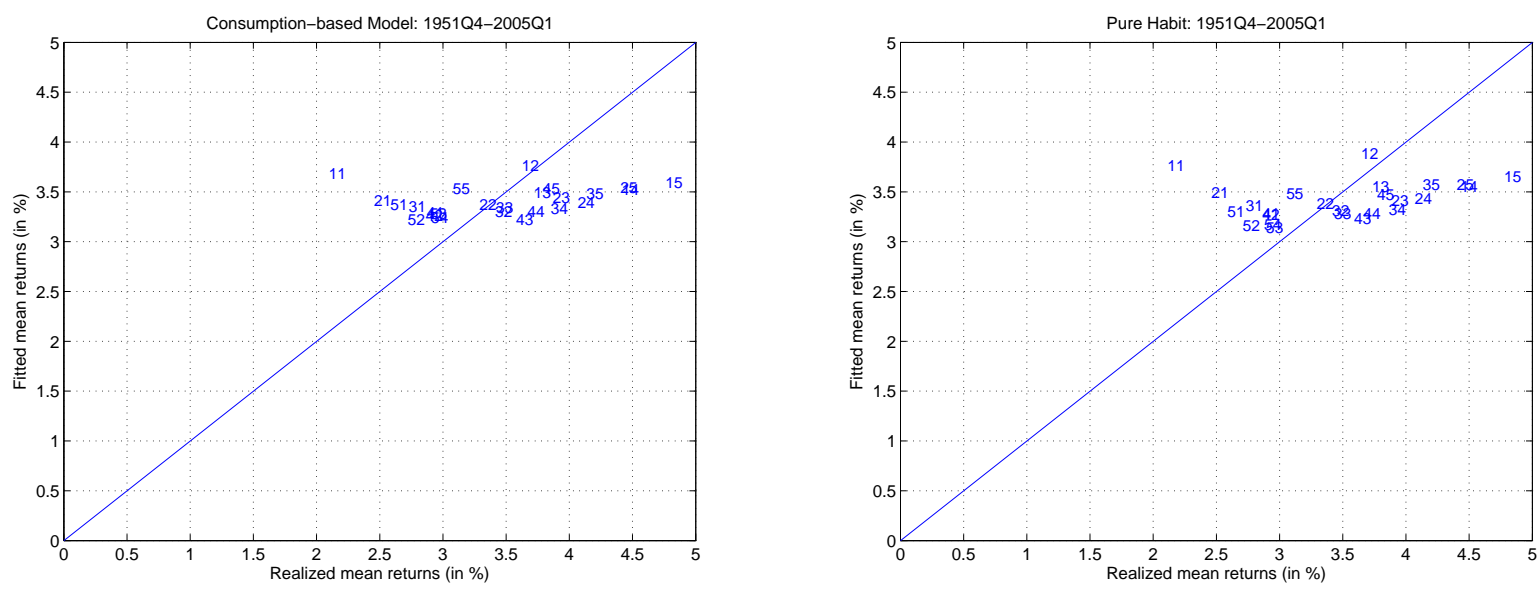

\section{Figure 1}

CCAPM with Power Utility and Pure Habit model: Fitted vs. Actual Mean Returns (in \% per Quarter)

Note: The graphs are based on first-stage GMM estimates using the 25 Fama-French portfolios as test assets. Realized mean returns are given on the horizontal axis, and the returns predicted by the model are provided on the vertical axis. The first digit represents the size quintiles $(1=$ small, $5=$ big) whereas the second digit refers to the book-to-market quintiles $(1=$ low, $5=$ big $)$. The sample period is 1951:Q4-2005:Q1. The two graphs show results for the nonlinear consumption-based model with power utility and the Pure Habit Model. 

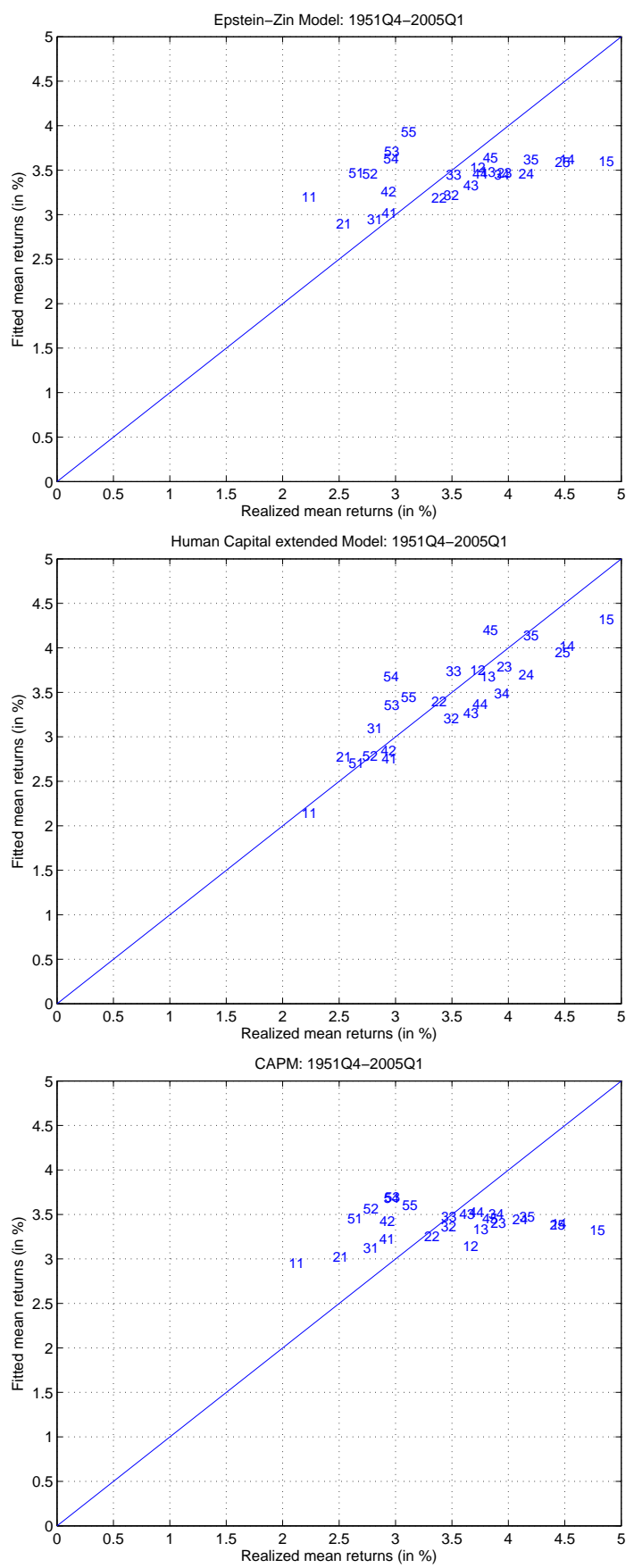
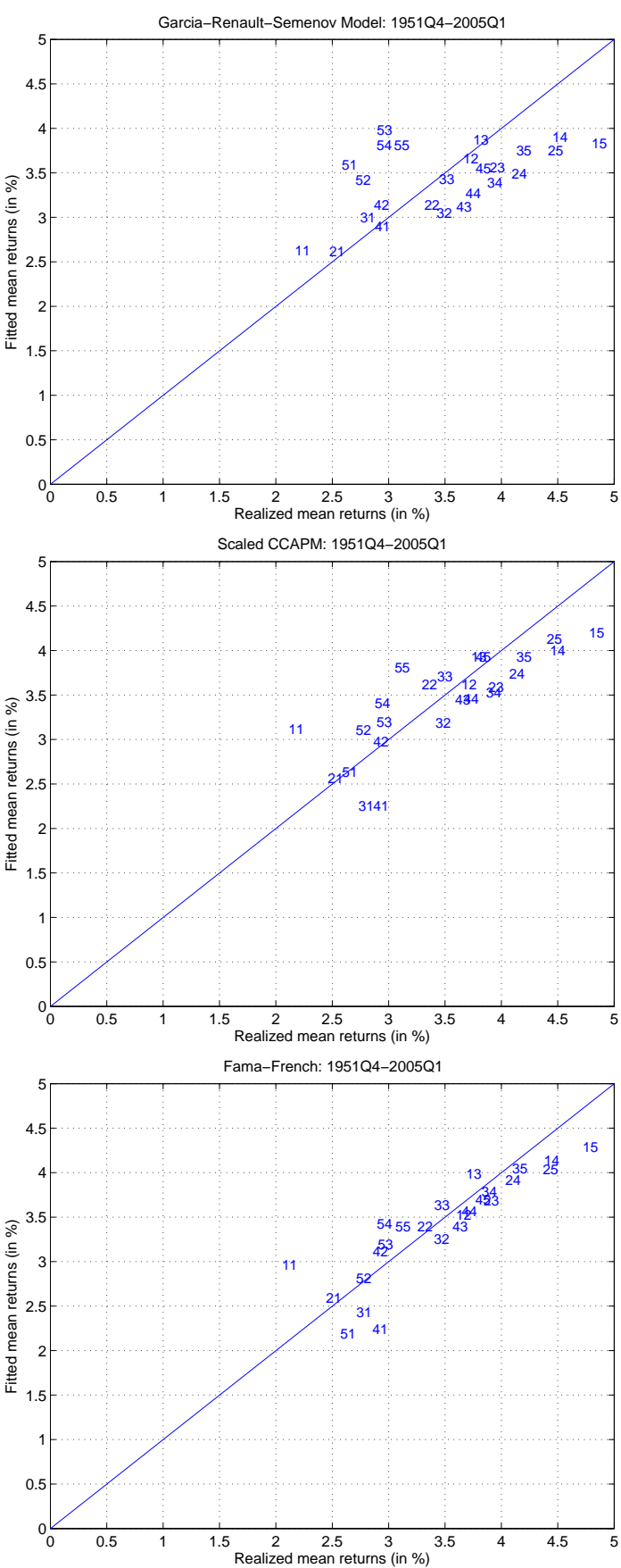

Figure 2

\section{Consumption-Based Asset Pricing Models and Benchmark Linear Factor Models: Fitted vs. Actual Mean Returns (in \% per Quarter)}

Note: The graphs are based on first-stage GMM estimates using the 25 Fama-French portfolios as test assets. Realized mean returns are given on the horizontal axis, and the returns predicted by the model are provided on the vertical axis. The first digit represents the size quintiles $(1=$ small, $5=\mathrm{big})$ whereas the second digit refers to the book-to-market quintiles $(1=$ low, 5=big). The sample period is 1951:Q4-2005:Q1. The upper two graphs show results for the Epstein-Zin Model and the Garcia-Renault-Semenov model. Below we display pricing error plots for the Human Capital Extended Model and the scaled CCAPM by Lettau and Ludvigson (2001a). Pricing error plots for the CAPM and the Fama-French model are shown at the bottom. 


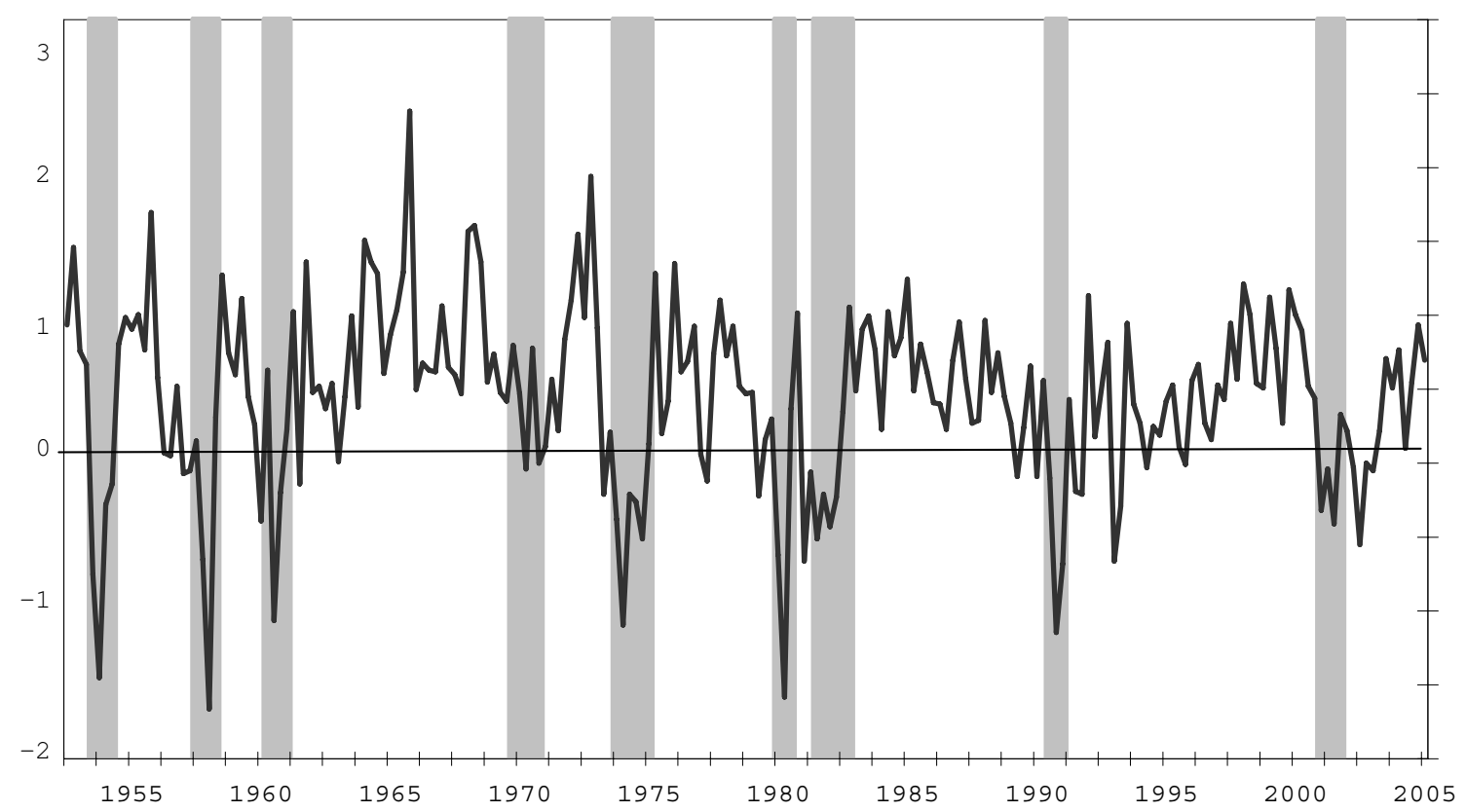

Figure 3

Consumption in Excess of the Reference Level

Note: The graph plots the evolution of consumption in excess of the reference level (in \%) over time. Grey-shaded are recession periods as identified by the NBER. The graph is based on the estimation results for the human capital augmented model in table 6. The sample period is 1951:Q4-2005:Q1. 